\title{
Rancang Bangun Sistem Informasi Parkir Mobil Otomatis Pada Gedung Bertingkat Berbasis Arduino Mega 2560
}

\author{
${ }^{a}$ Muhammad Ali Imron, ${ }^{b}$ Jamaaluddin \\ a,b Program Studi Teknik Elektro Universitas Muhammadiyah Sidoarjo \\ E-mail : Ali.imron09051995@gmail.com, Jamaaluddin@Umsida.ac.id
}

\begin{abstract}
Abstrak
Masalah yang sering timbul pada tempat parkir mobil seperti mall disetiap akhir pekan, banyak pengguna parkir kesulitan dan kebingungan untuk mencari tempat parkir yang kosong, sehingga pengguna parkir banyak membuang waktu hanya untuk mengelilingi area parkir. Melalui penelitian ini yang berjudul rancang bangun sistem informasi parkir mobil otomatis pada gedung bertingkat berbasis arduino mega 2560, diharapkan sistem ini mampu mempermudah pengguna parkir dalam mencari tempat parkir yang kosong tanpa harus mengelilingi area parkir. Pada penelitian ini membuat sebuah simulasi rancang bangun yang memanfaatkan komponen modul arduino mega 2560, LCD $4 \times 20$, motor servo, sensor inframerah. Prinsip kerja sistem adalah 2 sensor inframerah di pasang pada pintu masuk dan pintu keluar parkir, untuk membuka portal pintu masuk dan pintu keluar area parkir secara otomati digerakkan oleh motor servo, 8 sensor inframerah dipasang pada masing-masing tempat parkir berfungsi sebagai saklar otomatis, untuk menunjukkan bahwa masing-masing tempat parkir dalam keadaan kosong atau terisi. Kemudian arduino melakukan pengolahan data untuk ditampilkan dilayar LCD, dengan bentuk tampilan nomer masing-masing tempat parkir dan kondisi tempat parkir kosong atau terisi. Sehingga dapat menghasilkan efesiensi BBM dan efesiensi waktu.
\end{abstract}

Kata kunci : Rancang Bangun, Parkir Otomatis, Arduino Mega 2560

\section{Abstract}

Problems that often arise in the car park like a mall on every weekend, many parking users have trouble and confusion to find an empty parking lot, so parking lot users wasted time just to circle the parking area. Through this research entitled the design of automated car parking information system in arduino mega 2560-level building, it is expected that this system can facilitate parking users in searching for an empty parking space without having to surround the parking area. In this research, a design simulation that utilizes arduino mega 2560 module components, LCD 4x20, servo motor, infrared sensor. The working principle of the system are two infrared sensors in pairs at the entrance and exit parking, to open the portal entrance and exit the parking area is automatically driven by servo motor, 8 infrared sensors mounted on each parking lot serves as an automatic switch, for indicates that each parking lot is empty or filled. Then arduino perform data processing to display LCD screen, with the display form number of each parking lot and empty parking conditions or filled. So as to produce fuel efficiency and efficiency of time.

Keywords: Design Build, Parking Auto, Arduino Mega 2560

bertingkat seperti mall, sekarang masih banyak

\section{PENDAHULUAN}

Otomatisasi sudah menjadi sebuah keharusan karena dengan serba otomatis itu banyak sekali yang bisa dicapai, diantaranya adalah efisiensi dan kemudahan. Sistem yang otomatis tersebut dapat dibuat melalui perangkat-perangkat seperti $P C$ atau ARDUINO. Berdasarkan dari hasil pengamatan di area parkir mobil gedung-gedung kekurangan dan kendala terutama disetiap libur akhir pekan atau libur panjang sekolah. Karena tempat parkir yang tersedia dengan jumlah mobil yang ada tidak seimbang, sehingga pengguna parkir sering kesulitan dan kebingungan ketika mencari tempat parkir yang kosong, sampai harus mengelilingi area parkir tersebut berkali-kali. Dengan adanya permasalahan di atas maka diperlukan inovasi dalam bentuk sebuah sistem informasi dalam memberikan kemudahan kepada 
penggunakan parkir, untuk mencari tempat parkir yang kosong. Dengan ini penulis akan merancang sebuah sistem informasi otomatis yang dituangkan dalam proposal skripsi dengan judul "Rancang Bangun Sistem Informasi Parkir Mobil Otomatis Pada Gedung Bertingkat Berbasis Arduino Mega 2560.

\section{BAHASA DAN METODE}

A. Alat Dan Bahan Penelitian

Alat dan bahan bahan penelitian yang digunakan untuk membuat simulasi sistem informarsi parkir mobil otomatis pada gedung bertingkat berbasis arduino mega 2560 :

Alat :

1. Avo Meter Digital

2. Solder

3. Penyedot Timah

4. Obeng

5. Tang

6. Setrika

7. Software IDE Arduino

8. Software Proteus 7 Professional

9. Laptop ASUS K43U dengan spesifikasi sebagai berikut :

1. AMD E-450 APU

2. CPU@ $1.65 \mathrm{GHz}$

3. RAM 2GB

4. Sistem Operasi Windows 7 Ultimate

Bahan :

1. Modul Arduino Mega 2560

2. LCD $20 \times 4$

3. Motor Servo

4. Inframerah

5. Photodioda

6. Resistor

7. Papan PCB

8. Papan Akrilik

9. Timah

10. Kabel

11. Black Housing

B. Analisa Sistem

1. Blok Diagram

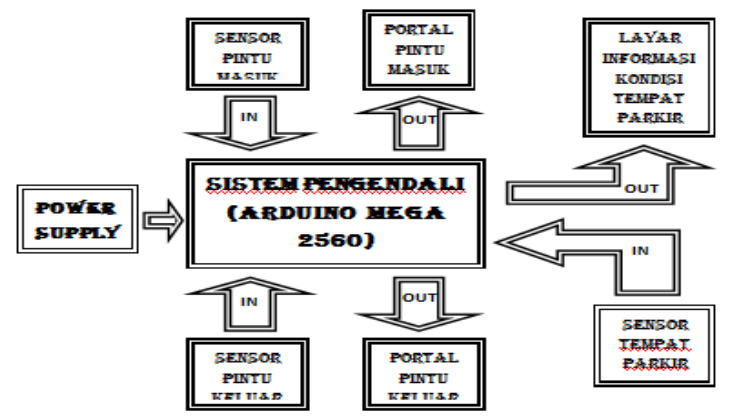

Gambar 1.1 Blok Diagram Rancang Bangun Sistem Infromasi Parkir Mobil Otomatis Pada Gedung Bertingkat Berbasis Arduino Mega 2560.

Pada gambar 1.1 menjelaskan blok diagram rancang bangun sistem informasi parkir mobil otomatis pada gedung bertingkat berbasis arduino mega 2560. Sistem rancang bangun ini dikendalikan oleh mikrokontroller arduino mega 2560 yang sudah diprogram sesuai pada sistem tersebut. Sensor inframerah berfungsi sebagai masukan (input), digunakan untuk mendeteksi suatu benda yang menghalanginya. Motor servo dan $L C D$ berfungsi sebagai keluaran (output), motor servo digunakan untuk menggerakkan portal pintu masuk dan pintu keluar, sedangkan $L C D$ digunakan untuk pemberi informasi kondisi tempat parkir mobil kepada pengguna parkir.

2. Flowchart Sistem

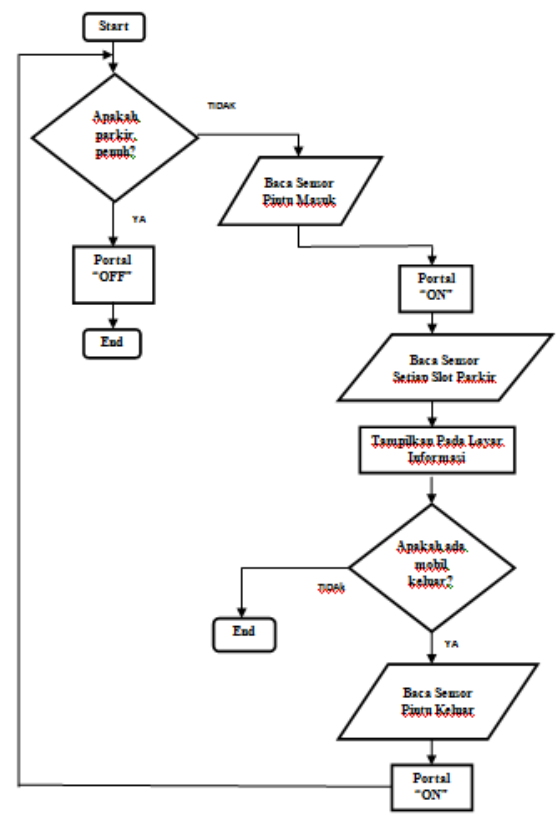

Gambar 1.2 Flowchart Rancang Bangun Sistem Informasi Parkir Mobil Otomatis Pada Gedung Bertingkat 
Gambar 1.2 menjelaskan flowchart cara kerja rancang bangun sistem informasi parkir mobil otomatis pada gedung bertingkat berbasis arduino mega 2560. Pada flowchart diatas Arduino akan menerima masukan (input) dari sensor inframerah yang diletakkan pada pintu masuk, kemudian arduino akan mengelolah masukan tersebut untuk menghidupkan motor servo agar portal pintu masuk terbuka, tetapi jika tempat parkir pada lantia 1 dan lantai 2 sudah penuh maka motor servo tidak akan berfungsi, sehingga mengakibatkan portal pintu masuk tidak akan terbuka. Arduino akan menerima masukan (input) dari sensor inframerah yang diletakkan pada setiap slot parkir, kemudian arduino makan mengelolah masukan tersebut untuk menampilkan kondisi tempat parkir yang terisi atau tidak terisi pada layar $L C D$ yang akan di pasang pada pintu masuk. Arduino akan menerima masukan dari sensor inframerah yang diletakkan pada pintu keluar, kemudian arduino akan mengelolah masukan tersebut untuk menghidupkan motor servo agar portal pintu keluar terbuka. Sistem tersebut akan tetap terus berjalan apabila Arduino diberi sumber tegangan dari power supply.

C. Desain Rancang Bangun

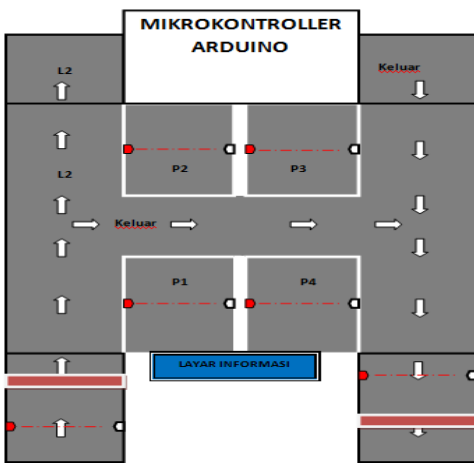

Gambar 1.3 Desain Lantai 1 Rancang Bangun Sistem Informasi Parkir Mobil Otomatis Pada Gedung Bertingkat

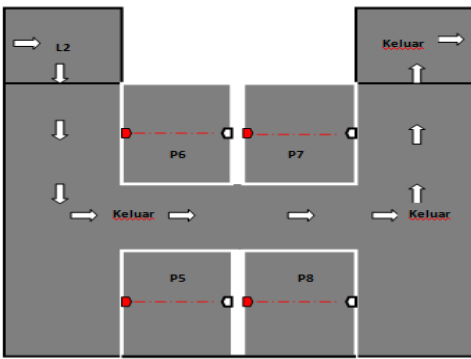

Gambar 1.4 Desain Lantai 2 Rancang Bangun Sistem Informasi Parkir Mobil Otomatis Pada Gedung Bertingkat
Pada gambar 1.3 dan 1.4 menjelaskan desain rancang bangun yang akan dibuat sistem informasi parkir mobil otomatis pada gedung bertingkat. Pada desain ini dibuat dua lantai tempat parkir, lantai pertama berkapasistas 4 mobil dan lantai kedua berkapasitas 4 mobil dimana setiap slot parkir mobil dipasang sensor infra merah. Untuk masing - masing pintu masuk dan pintu keluar dipasang porta, kemudian sebelum pintu masuk dipasang LCD berukuran $20 \times 4$ digunakan sebagai pemberi informasi kondisi tempat parkir kepada pengguna parkir yang akan memasuki area parkir tersebut.

\section{HASIL DAN PEMBAHASAN}

A. Pengujian Rangkaian Sensor Inframerah

Tabel 1.1 Hasil Pengujian Rangkain Sensor Inframerah

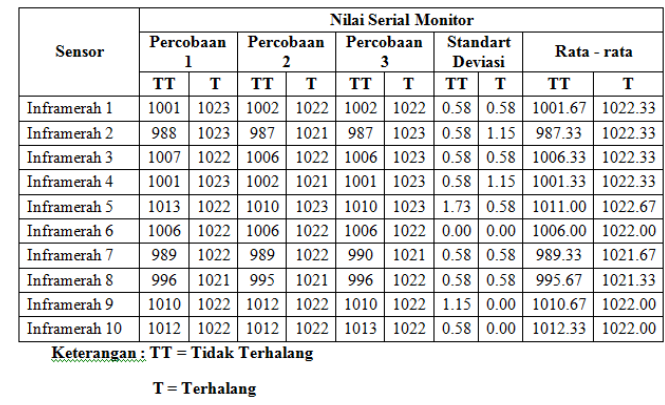

Berikut perhitungan standart deviasi secara manual sebanyak 2 contoh, untuk perhitungan secara keseluruhan bisa dilihat pada lampiran 1:

1. Inframerah 1

Kondisi Tidak Terhalang

Varian $\quad=\frac{\sum_{i=1}^{5}(X i-X) 2}{n-1}$

$=$

$(1001-1001.7) 2+(1002-1001.7) 2+(1002-1001.7) 2$ $3-1$

$$
=\frac{0.67}{3-1}
$$

Standart Deviasi

$$
=\sqrt{\frac{0.67}{3-1}}=\sqrt{0.335}=0.57879
$$

Kondisi Terhalang

Varian

$$
=\frac{\sum_{i=1}^{5}(X i-X) 2}{n-1}
$$


$(1023-1022.3) 2+(1022-1022.3) 2+(1022-1022.3) 2$

$$
=\frac{0.67}{3-1}
$$

Standart Deviasi

$$
=\sqrt{\frac{0.67}{3-1}}=\sqrt{0.335}=0.57879
$$

2. Inframerah 2

Kondisi Tidak Terhalang

$$
\begin{aligned}
& \text { Varian }=\frac{\sum_{i=1}^{5}(X i-X) 2}{n-1} \\
&= \\
& \frac{(988-987.3) 2+(987-987.3) 2+(987-987.3) 2}{3-1} \\
&=\frac{0.67}{3-1}
\end{aligned}
$$

Standart Deviasi

$$
=\sqrt{\frac{0.67}{3-1}}=\sqrt{0.335}=0.57879
$$

Kondisi Terhalang

Varian

$$
=\frac{\sum_{i=1}^{5}(X i-X) 2}{n-1}
$$

$(1023-1022.3) 2+(1021-1022.3) 2+(1023-1022.3) 2$ $3-1$

$$
=\frac{2.69}{3-1}
$$

Standart Deviasi

$$
=\sqrt{\frac{2.69}{3-1}}=\sqrt{1.335}=1.155422
$$

Hasil dari pengujian 10 rangkaian sensor inframerah dengan melakukan 3 kali percobaan, kondisi nilai serial yang keluar ketika sensor inframerah dalam keadaan tidak terhalang menjadi terhalang mengalami kenaikan nilai serialnya, karena disebabkan adanya perubahan

\begin{tabular}{|c|c|c|c|c|c|c|c|c|c|c|c|c|}
\hline \multirow{3}{*}{$\begin{array}{c}\text { Sudut } \\
\text { Putaran } \\
\left(^{\circ}\right)\end{array}$} & \multicolumn{12}{|c|}{ Kondisi Putaran Motor Servo } \\
\hline & \multicolumn{2}{|c|}{$\begin{array}{c}\text { Percobaan } \\
1\end{array}$} & \multicolumn{2}{|c|}{$\begin{array}{c}\text { Percobaan } \\
2\end{array}$} & \multicolumn{2}{|c|}{$\begin{array}{c}\text { Percobaan } \\
3\end{array}$} & \multicolumn{2}{|c|}{$\begin{array}{c}\text { Standart } \\
\text { Deviasi }\end{array}$} & \multicolumn{2}{|c|}{ Rata - rata } & \multicolumn{2}{|c|}{ Ketepatan $\%$} \\
\hline & $\mathrm{Sl}\left({ }^{\circ}\right)$ & S2 $\left(^{\circ}\right)$ & $\mathrm{Sl}\left({ }^{\circ}\right)$ & $\left.\mathrm{S} 22^{\circ}\right)$ & $\mathrm{Sl}\left({ }^{\circ}\right)$ & $\left.\mathrm{S} 20^{\circ}\right)$ & Sl & S2 & $\mathrm{S} 1\left(^{\circ}\right)$ & $\left.\mathrm{S} 22^{\circ}\right)$ & S1 & $\mathrm{S}_{2}$ \\
\hline 45 & 50 & 50 & & 50 & 5 & 56 & & 0 & 50 & 50 & $9 \%$ & 899 \\
\hline 90 & 100 & 100 & 100 & 100 & 100 & 100 & 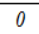 & 0 & 100 & 100 & $89 \%$ & $89 \%$ \\
\hline 60 & 70 & 70 & 70 & 70 & 70 & 70 & 0 & 0 & 70 & 70 & $83 \%$ & $83 \%$ \\
\hline 100 & 112 & 110 & 112 & 110 & 112 & 110 & 0 & 0 & 112 & 110 & $88 \%$ & $90 \%$ \\
\hline
\end{tabular}
resistensi dari rangkaian inframerah tersebut. Tetapi dalam keadaan tidak terhalang maupun terhalang dari 10 rangkaian sensor inframerah dengan melakukan 3 kali percobaan nilai serial yang keluar berbeda - beda, dibuktikan dengan nilai standar deviasi yang tidak sama yaitu antara 0,00 sampai 1,73 .

B. Pengujian Rangkaian Motor Servo

Tabel 1.2 Pengujian Rangkaian Motor Servo
Keterangan: $\mathrm{Sl}=$ Servo 1

S2 $=$ Servo 2

Berikut perhitungan standart deviasi dan ketepatan secara manual sebanyak 2 contoh, untuk perhitungan secara keseluruhan bisa dilihat pada lampiran 1.

1. Sudut Putar $45^{\circ}$

Pada Servo 1

Varian $\quad=\frac{\sum_{i=1}^{5}(X i-X) 2}{n-1}$

$$
\begin{gathered}
=\frac{(50-50) 2+(50-50) 2+(50-50) 2}{3-1} \\
=\frac{0^{3-1}}{3-1}
\end{gathered}
$$

Standart Deviasi

$$
=\sqrt{\frac{0}{3-1}}=\sqrt{0}=0
$$

$$
\begin{aligned}
\% \text { Ketepatan } & =1-\left\{\left|\frac{50-45}{45}\right|\right\} \times 100 \% \\
& =1-\{0.11\} * 100 \% \\
& =89 \%
\end{aligned}
$$

Pada Servo 2

Varian $\quad=\frac{\sum_{i=1}^{5}(X i-X) 2}{n-1}$

Standart Deviasi

$$
=
$$

$(50-50) 2+(50-50) 2+(50-50) 2$

$$
=\frac{0^{3-1}}{3-1}
$$

$$
=\sqrt{\frac{0}{3-1}}=\sqrt{0}=0
$$

$\%$ Ketepatan $=1$ -

$\left\{\left|\frac{50-45}{45}\right|\right\} \times 100 \%$

$$
\begin{aligned}
& =1-\{0.11\} * 100 \% \\
& =89 \%
\end{aligned}
$$

2. Sudut Putar $90^{\circ}$

Pada Servo 1

Varian

$$
=\frac{\sum_{i=1}^{5}(X i-X)_{2}}{n-1}
$$


$=$

$\frac{(100-100) 2+(100-100) 2+(100-100) 2}{3-1}$

Standart Deviasi

$$
=\frac{0}{3-1}
$$

$$
=\sqrt{\frac{0}{3-1}}=\sqrt{0}=0
$$

$$
\begin{aligned}
\% \text { Ketepatan } & =1- \\
\left\{\left|\frac{100-90}{90}\right|\right\} \times 100 \% & \\
& =1-\{0.11\} * 100 \% \\
& =89 \%
\end{aligned}
$$

Pada Servo 2

Varian

$$
=\frac{\sum_{i=1}^{5}(X i-X) 2}{n-1}
$$$$
=
$$

$\underline{(100-100) 2+(100-100) 2+(100-100) 2}$

$$
\text { 3-1 }
$$

Standart Deviasi

$$
=\frac{0}{3-1}
$$

$$
=\sqrt{\frac{0}{3-1}}=\sqrt{0}=0
$$

$\left\{\left|\frac{100-90}{90}\right|\right\} \times 100 \%$

$$
\begin{aligned}
& =1-\{0.11\} * 100 \% \\
& =89 \%
\end{aligned}
$$

Dari hasil pengujian motor servo pada percobaan 1, ketika program arduino diberi sudut putar $45^{\circ}$ motor servo 1 dan motor servo 2 berputar sebesar $50^{\circ}$ dengan ketepatan sudut putar sebesar $89 \%$, ketika program arduino diberi sudut putar $90^{\circ}$ motor servo 1 dan motor servo 2 berputar sebesar $100^{\circ}$ dengan ketepatan sudut putar $89 \%$, ketika program arduino diberi sudut putar $60^{\circ}$ motor servo 1 dan motor servo 2 berputar sebesar $70^{\circ}$ dengan ketepatan sudut putar sebesar $83 \%$, ketika program arduino diberi sudut putar $100^{\circ}$ motor servo 1 berputar 112 dan motor servo 2 berputar $110^{\circ}$ dengan ketepatan sudut putar sebesar $88 \%$ dan $90 \%$. Jadi 2 motor servo dari 3 kali percobaan dengan sudut yang berbeda - beda putaran motor servo dalam kondisi stabil, dibuktikan dengan nilai standart deviasi yang sama yaitu 0 .
C. Pengujian Sistem Keseluruhan

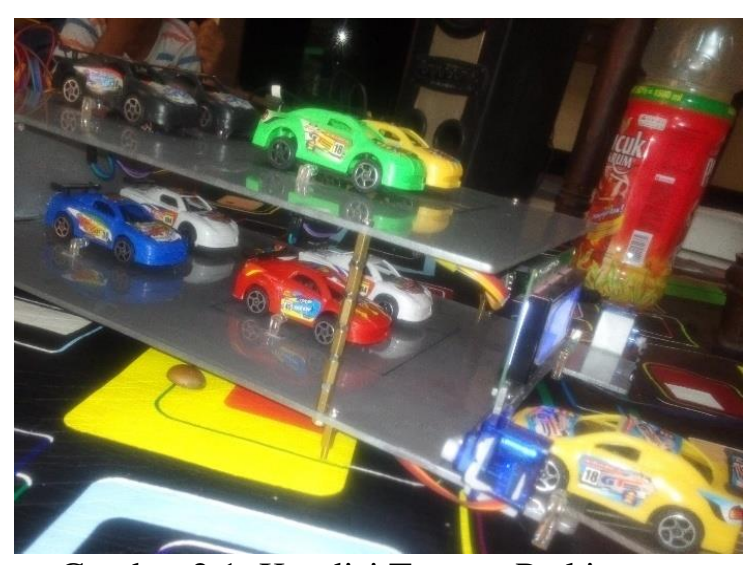

Gambar 2.1 Kondisi Tempat Parkir Penuh dan Pintu Masuk OFF

Pada gambar 2.1 menunjukkan bawha parkir dalam kondisi penuh, sehingga mobil yang ingin masuk ke area parkir tidak bisa masuk, karena ketika kondisi parkir penuh portal pintu masuk dalam kondisi OFF, apabila ada salah satu

\begin{tabular}{|c|c|c|c|c|c|c|c|c|c|c|c|}
\hline \multicolumn{8}{|c|}{ KONDISI TEMPAT PARKIR } & \multirow{3}{*}{\multicolumn{2}{|c|}{ TAMPILAN LAYAR LCD }} & \multicolumn{2}{|c|}{ KONDISI } \\
\hline \multicolumn{4}{|c|}{ LANTAI 1} & \multicolumn{4}{|c|}{ LANTAI 2} & & & \multirow{2}{*}{$\begin{array}{c}\text { PINTU } \\
\text { MASUK }\end{array}$} & \multirow{2}{*}{$\begin{array}{c}\text { PINTU } \\
\text { KELUAR }\end{array}$} \\
\hline P1 & P2 & P3 & P4 & P5 & P6 & P7 & P8 & & & & \\
\hline \multirow{2}{*}{ IN } & \multirow{2}{*}{ IN } & \multirow{2}{*}{\begin{tabular}{|l}
$\mathrm{O}$ \\
$\mathrm{U}$ \\
$\mathrm{T}$
\end{tabular}} & \multirow{2}{*}{$\begin{array}{l}\mathrm{O} \\
\mathrm{U} \\
\mathrm{T}\end{array}$} & \multirow{2}{*}{$\begin{array}{l}\mathrm{O} \\
\mathrm{U} \\
\mathrm{T}\end{array}$} & \multirow{2}{*}{\begin{tabular}{|l|}
$\mathrm{O}$ \\
$\mathrm{U}$ \\
$\mathrm{T}$
\end{tabular}} & \multirow{2}{*}{$\begin{array}{l}\mathrm{O} \\
\mathrm{U} \\
\mathrm{T}\end{array}$} & \multirow{2}{*}{$\begin{array}{l}\mathrm{O} \\
\mathrm{U} \\
\mathrm{T}\end{array}$} & L2 & $\begin{array}{|ll|}\text { P7:OUT } & \text { P8:OUT } \\
\text { P5:OUT } & \text { P6:OUT } \\
\end{array}$ & \multirow{2}{*}{ ON } & \multirow{2}{*}{ ON } \\
\hline & & & & & & & & Ll & $\begin{array}{|ll|}\text { P3:OUT } & \text { P4:OUT } \\
\text { P1:IN } & \text { P2:IN } \\
\end{array}$ & & \\
\hline \multirow{2}{*}{ IN } & \multirow{2}{*}{ IN } & \multirow{2}{*}{ IN } & \multirow{2}{*}{ IN } & \multirow{2}{*}{$\begin{array}{l}\mathrm{O} \\
\mathrm{U} \\
\mathrm{T}\end{array}$} & \multirow{2}{*}{$\begin{array}{l}\mathrm{O} \\
\mathrm{U} \\
\mathrm{T}\end{array}$} & \multirow{2}{*}{$\begin{array}{l}\mathrm{O} \\
\mathrm{U} \\
\mathrm{T}\end{array}$} & \multirow{2}{*}{$\begin{array}{l}\mathrm{O} \\
\mathrm{U} \\
\mathrm{T}\end{array}$} & L2 & $\begin{array}{ll}\text { P7:OUT } & \text { P8:OUT } \\
\text { P5:OUT } & \text { P6:OUT }\end{array}$ & \multirow{2}{*}{ ON } & \multirow{2}{*}{$\mathrm{ON}$} \\
\hline & & & & & & & & L1 & \begin{tabular}{|ll} 
P3:IN & P4:IN \\
P1:IN & P2:IN \\
\end{tabular} & & \\
\hline \multirow{2}{*}{ IN } & \multirow{2}{*}{ IN } & \multirow{2}{*}{ IN } & \multirow{2}{*}{ IN } & \multirow[b]{2}{*}{ IN } & \multirow{2}{*}{ IN } & \multirow[t]{2}{*}{$\begin{array}{l}\mathrm{O} \\
\mathrm{U}\end{array}$} & \multirow{2}{*}{$\begin{array}{l}\mathrm{O} \\
\mathrm{U} \\
\mathrm{T}\end{array}$} & L2 & \begin{tabular}{|ll} 
P7:OUT & P8:OUT \\
P5:IN & P6:IN \\
\end{tabular} & \multirow{2}{*}{ ON } & \multirow{2}{*}{ ON } \\
\hline & & & & & & & & L1 & \begin{tabular}{|ll} 
P3:IN & P4:IN \\
P1:IN & P2:IN \\
\end{tabular} & & \\
\hline \multirow[b]{2}{*}{ IN } & & & & & & & & L2 & \begin{tabular}{|ll} 
P7:IN & P8:IN \\
P5:IN & P6:IN \\
\end{tabular} & & \\
\hline & IN & IN & IN & IN & IN & IN & IN & Ll & $\begin{array}{|ll|}\text { P3:IN } & \text { P4:IN } \\
\text { P1:IN } & \text { P2:IN } \\
\end{array}$ & OFF & ON \\
\hline
\end{tabular}
mobil yang keluar, maka portal pintu masuk dalam kondisi ON yang artinya portal bisa membuka dan menutup jika ada mobil yang ingin masuk ke area parkir. Jadi pada portal pintu masuk dan pintu keluar menggunakan sistem counter (penghitungan), guna untuk membatasi jumlah mobil yang akan masuk sesuai kapasitas area parkir mobil.

Tabel 1.3 Pengujian Sistem Informasi

Parkir Mobil Otomatis Pada Gedung Bertingkat

Dari hasil pengujian alat sistem informasi parkir mobil otomatis pada gedung bertingkat dinyatakan dalan kondisi baik, dibuktikan dengan pintu masuk dan pintu keluar yeng membuka dan menutup secara otomatis, 8 rangkaian sensor yg terpasang pada tempat parkir bisa menampilkan kondisi tempat parkir pada layar informasi, ketika tempat parkir sudah penuh pintu masuk tidak 
akan bisa membuka secara otomatis sampai dengan kondisi tempat parkir ada yang kosong.

\section{Kesimpulan}

Setelah dilakukan pengujian sistem informasi parkir mobil otomatis pada gedung bertingkat berbasis arduino mega 2560 dapat ditarik kesimpulan sebagai berikut:

1. Sistem yang dibuat dalam bentuk rancang bangun miniatur ini dapat menjadi solusi untuk diaplikasi dalam dunia perparkiran pada gedung bertingkat

2. Rancang bangun ini di desain menggunakan sensor inframerah sebagai otomatisasi yang dihubungan pada layar informasi, portal pintu masuk dan portal pintu keluar.

3. Rancang bangun ini dapat bekerja sesuai apa yang diharapkan, tanpa ada kendala.

\section{Daftar Pustaka}

[1] A. G. Sanjaya, "PROTOTIPE SISTEM INFORMASI KENDALI PARKIR BERBASIS WEB DENGAN INFORMASI RUANG PARKIR TERSEDIA MENGGUNAKAN TAMPILAN SEVEN SEGMENT.” 2012.

[2] Betty Nurlia Dewi, "Perancangan dan Simulasi Sistem Manajemen Parkir pada Area Parkir Bertingkat,” 2014.

[3] E. Yudaningtyas, "Sistem kontrol kecepatan motor dc d-6759 berbasis arduino mega 2560," pp. 1-6.

[4] D. M. Timpanometri, "Universitas Sumatera Utara," pp. 16-37, 2012.

[5] G. Magdalena, A. Aribowo, and F. Ati Halim, "Perancangan sistem akses pintu garasi otomatis menggunakan platform Android," Pros. Conf. Smart-Green Technol. Electr. Inf. Syst., vol. D-025, no. November, pp. 301-306, 2013.

[6] K. Ruangan, P. Rumah, and T. Akhir, "Aplikasi mikrokontroler at89c51 untuk keamanan ruangan pada rumah cerdas," pp. 199, 2004.

[7] Y. Ardianto Pranata, Syaiful Nur Arif, "Perancangan Prototipe Sistem Parkir Cerdas," pp. 131-140, 2015. 